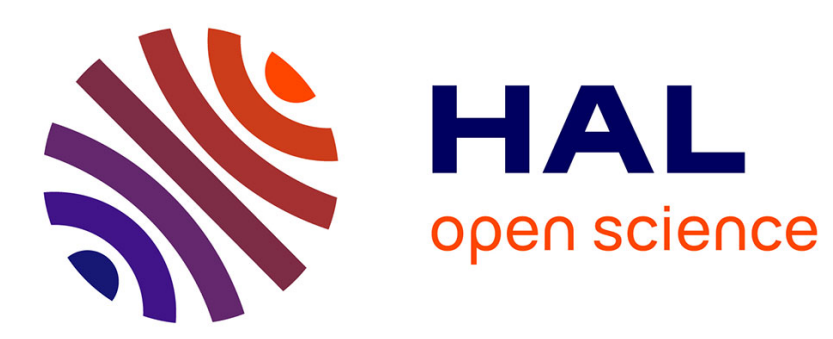

\title{
Fluxgate vector magnetometers: A multisensor device for ground, UAV, and airborne magnetic surveys
} Bruno Gavazzi, Pauline Le Maire, Marc Munschy, Aline Dechamp

\section{To cite this version:}

Bruno Gavazzi, Pauline Le Maire, Marc Munschy, Aline Dechamp. Fluxgate vector magnetometers: A multisensor device for ground, UAV, and airborne magnetic surveys. Leading Edge, 2016, 35 (9), pp.795-797. 10.1190/tle35090795.1. hal-01624847

\section{HAL Id: hal-01624847 https://hal.science/hal-01624847}

Submitted on 27 Oct 2017

HAL is a multi-disciplinary open access archive for the deposit and dissemination of scientific research documents, whether they are published or not. The documents may come from teaching and research institutions in France or abroad, or from public or private research centers.
L'archive ouverte pluridisciplinaire HAL, est destinée au dépôt et à la diffusion de documents scientifiques de niveau recherche, publiés ou non, émanant des établissements d'enseignement et de recherche français ou étrangers, des laboratoires publics ou privés. 


\title{
Fluxgate vector magnetometers: A multisensor device for ground, UAV, and airborne magnetic surveys
}

\author{
Bruno Gavazzi ${ }^{1}$, Pauline Le Maire ${ }^{1,3}$, Marc Munschy ${ }^{1}$, and Aline Dechamp ${ }^{2}$
}

\section{Abstract}

Fluxgate magnetometers are quite uncommon in geophysics. Recent advances in calibration of the devices and their magnetic compensation ability led Institut de Physique du Globe de Strasbourg to develop instruments for magnetic measurements at different scales for a wide range of applications - from submetric measurements on the ground to aircraft-conducted acquisition by unmanned aerial vehicles (UAVs). A case study on the aerial military base BA112 shows the usefulness of the instruments for the detection of underground pipes, unexploded ordnance, and archaeological remains.

\section{Introduction}

Magnetic methods are used for various applications, such as mining exploration, unexploded-ordnance (UXO) detection, and archaeology (Nabighian et al., 2005). The concept is always the same: measuring the lateral variations in the magnetic field due to the heterogeneities of magnetization within the ground. Depending on the survey's purpose, the measurements can be conducted at a wide range of scales, from a few square meters on the ground to square kilometers at high altitudes. Generally, magnetic data are obtained with scalar magnetometers using opticalpumping or proton-precession principles. They give a pseudoabsolute value of the total magnetic intensity (TMI) of the field. However, this technique has a few limits.

Magnetometers based on precession (proton and Overhauser) are rugged and quite simple. They offer a sensitivity of about 0.1 nanotesla $(\mathrm{nT})$, but the sampling rate cannot exceed a few hertz, which can be problematic for measurements at a high speed or for measuring time variations at a higher frequency. Magnetometers based on optical pumping have a high sensitivity, usually under $0.01 \mathrm{nT}$. The acquisition rate is up to a few tenths of hertz, but they are quite complex and more fragile than the precession type. In any case, the measured TMI includes the magnetic effect of the equipment itself, which is a problem for precise measurements. The bigger the magnetized equipment is, the farther away from the magnetometer it should be installed. As a consequence, compact devices are difficult to design. We overcome these limitations through the use of fluxgate vector magnetometers.

\section{Fluxgate vector magnetometers}

Fluxgate vector magnetometers are purely electronic devices (Primdahl, 1979). They are resistant, light, and do not need a lot of energy to function. They are relative instruments and allow us to measure the intensity of the magnetic field in the direction of a sensor. Three sensors are installed orthogonally to measure each component of the magnetic field, and both the intensity and direction can be computed. As a consequence, their precision is highly dependent on the quality of their orientation. Available inertial measurement units are not precise enough to obtain a sensitivity better than a few hundred nT. Therefore, the use of fluxgate is generally limited to proceed to a heading correction in airborne surveys. However, earlier work on calibration and magnetic compensation of the equipment shows that both can be computed together from a simple procedure in the field. Thus, the TMI can be computed with a sensitivity of about $1 \mathrm{nT}$ (Munschy et al., 2007). Such precision is achievable even when the effect of the equipment can reach up to a few thousand nT (Bronner et al., 2013). This feature allows the design of a compact solution for different scales of study.

\section{Devices developed by IPGS}

At Institut de Physique du Globe de Strasbourg (IPGS), we develop equipment for magnetic measurements using fluxgates. In-house-built electronics power the instruments and digitize and store the data. Two versions are presently in use. The standard version has inputs for up to eight magnetometers, two global navigation satellite system (GNSS) antennae, and a controller. It also includes a PC and an SVGA port for realtime display of data. The entire weight is approximately $4 \mathrm{~kg}$, and the device can run for six hours (Figure 1a). The light

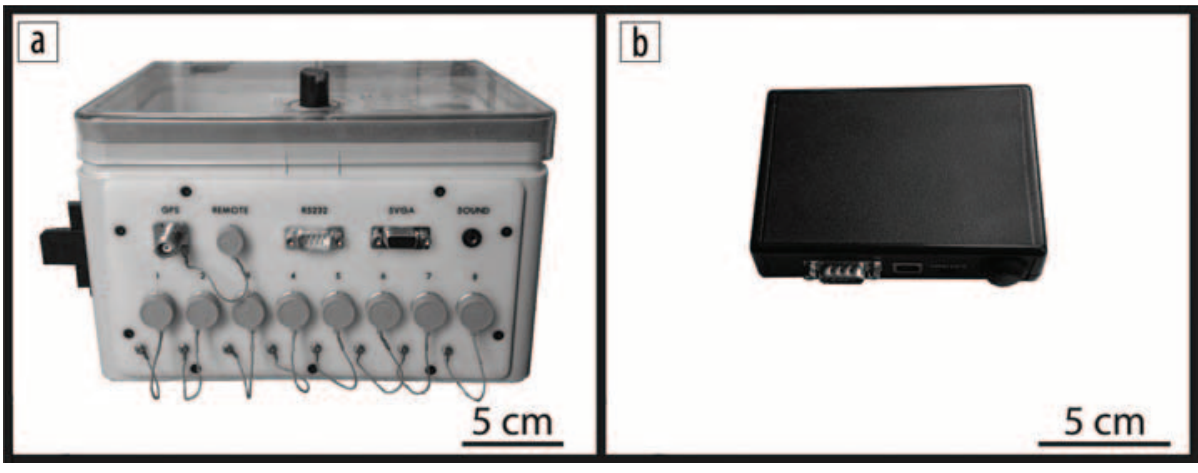

Figure 1. Electronics developed by IPGS: (a) standard version; (b) light version.

${ }^{1}$ UMR 7516, Institut de Physique du Globe de Strasbourg, École et $\quad$ http://dx.doi.org/10.1190/tle35090795.1.

${ }^{3}$ CARDEM. 
version has inputs for one magnetometer and one GNSS antenna. A push-up button serves as controller. The light version weighs approximately $0.2 \mathrm{~kg}$ and can run for four hours (Figure 1b). The two devices can cover a large range of applications on different frames. The standard version is used for ground and heavy airborne surveys, while the lighter version is used for UAV or small-aircraft surveys. Both are used with Bartington Mag-03 MC fluxgate magnetometers.

\section{Case study: Aerial Base BA112, Reims, France}

The case study focuses on the aerial base BA112 of the French army (Figure 2a). It was built in 1909 and was heavily bombed during the two world wars. Between 1979 and 2007, 1900 pieces of unexploded ordnance (UXO) have been removed from the ground (Figure $2 \mathrm{~b}$ ). UXO, ammunition stocks, trenches, tunnels, and shelters are expected. To investigate the subsurface, we conducted magnetic measurements at different scales.

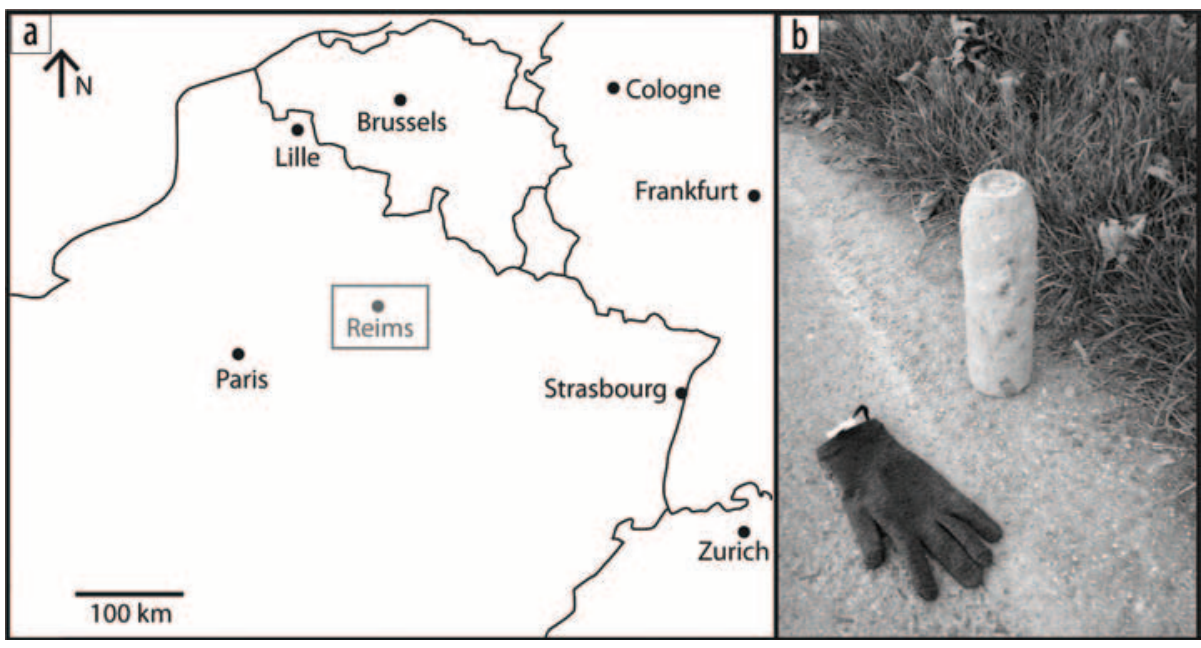

Figure 2. (a) Case-study localization indicated by rectangle. (b) Example of unexploded ordnance found on the site.

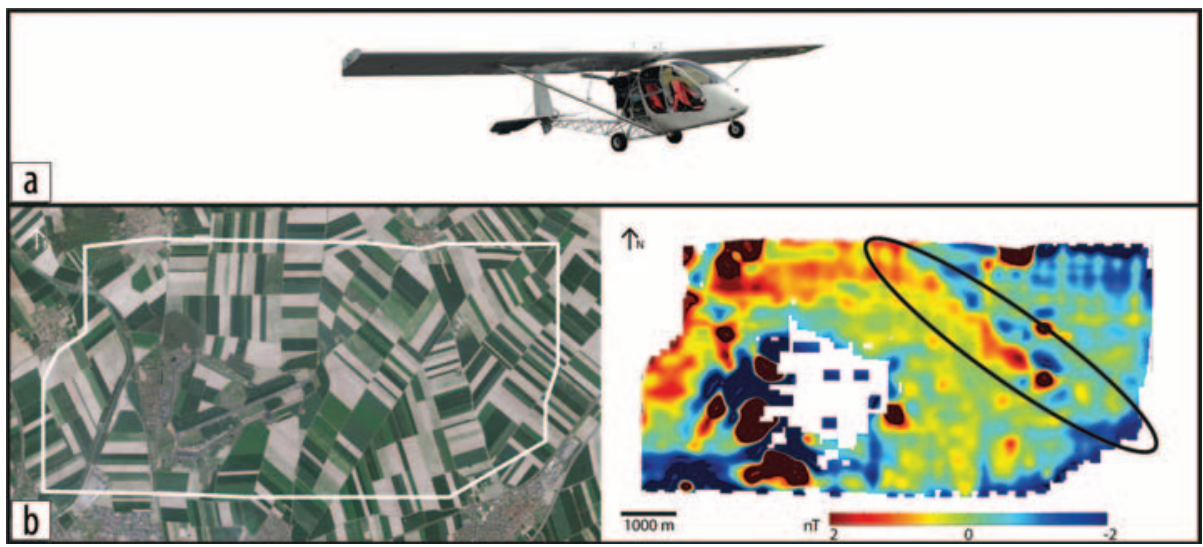

Figure 3. (a) Ultralight aircraft used by L'Europe vue du ciel for the survey. (b) Limits of the survey over satellite images (SPOT 6-7 made available by IGN at http://www.geoportail.gouv.fr) to the left. Map of the total magnetic field anomaly to the right. The linear anomaly corresponding to the pipeline is highlighted in black.

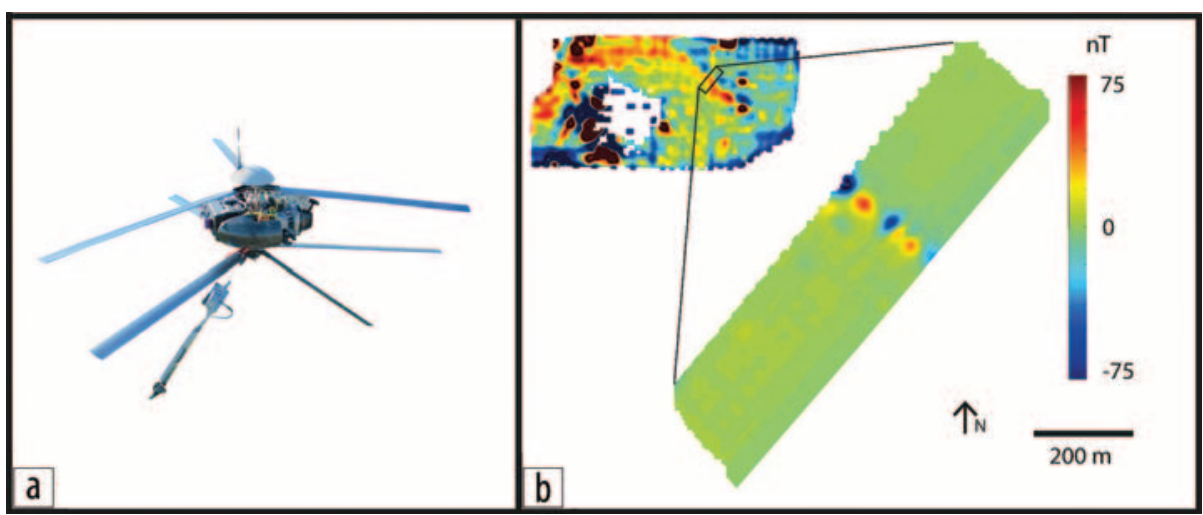

Figure 4. (a) UAV IT-180 from ECA ROBOTICS. (b) Map of the magnetic anomalies obtained with the UAV $5 \mathrm{~m}$ above the ground.
Ultralight aircraft. The first survey was conducted by L'Europe vue du ciel with an ultralight aircraft (Figure 3a). Magnetic profiles were measured every $100 \mathrm{~m}$ and tie lines every $300 \mathrm{~m}$ at an elevation of $100 \mathrm{~m}$ above the ground. Approximately 2,000,000 $\mathrm{m}^{2}$ were covered per hour of measurement. The central part of the survey area has no coverage because the activity of two military units disturbed the aircraft electronics. The results show dipolar anomalies, which correspond to buildings visible on the surface. In addition, a northwest-southeast lineation appears in the eastern part of the area (Figure 3b). Its amplitude is about $2 \mathrm{nT}$, just above the resolution of the calibrated magnetometers. It corresponds to a known pipeline.

Unmanned aerial vehicle. To improve the details, part of the pipeline was surveyed by ECA ROBOTICS with an IT-180 UAV. Magnetic profiles are acquired every $10 \mathrm{~m}$ at $5 \mathrm{~m}$ above the ground (Figures $4 \mathrm{a}$ and $4 \mathrm{~b}$ ). Approximately $100,000 \mathrm{~m}^{2}$ are covered per hour of measurement. The results show an alignment of dipoles corresponding to sections of the pipeline. The amplitude of the dipolar anomalies is about $100 \mathrm{nT}$.

Ground (0.5 m spacing, $1 \mathrm{~m}$ above the ground). In the central area, closer to the buildings, different targets are expected: underground pipes, World War I (WWI) trenches, and numerous UXO. To have a high resolution, measurements were collected on the ground surface. A device mounted on a backpack and developed by IPGS was used (Figure 5a). It allows the simultaneous acquisition of up to eight magnetic profiles spaced every $0.5 \mathrm{~m}$ at a height of $1 \mathrm{~m}$ above the ground. With six magnetometers, typical survey production rate for profiles and tie lines can 
be up to approximately $10,000 \mathrm{~m}^{2}$ per hour. The results reveal the presence of different lineations corresponding to underground pipes, as well as trenches from WWI, with an amplitude ranging from a few to $150 \mathrm{nT}$. Numerous dipolar anomalies can also be noted. They probably correspond to UXO (Figure 5b). The depth, horizontal position, and magnetization of the bodies of the sources of such dipolar anomalies can be estimated by inversion on the analytic signal (Munschy et al., 2007).

\section{Ground (0.2 $\mathrm{m}$ spacing, $0.2 \mathrm{~m}$ above} the ground). A device mounted on a sledge and developed by IPGS was used to improve the details around the WWI trenches (Figure 6a). It allows the simultaneous acquisition of up to eight magnetic profiles every $0.2 \mathrm{~m}$ at $0.2 \mathrm{~m}$ above the ground. With five magnetometers, the production rate of profiles and tie lines was approximately $2000 \mathrm{~m}^{2}$ per hour. The results show more details of the geometry of the trenches. The amplitude of the signal is more than doubled

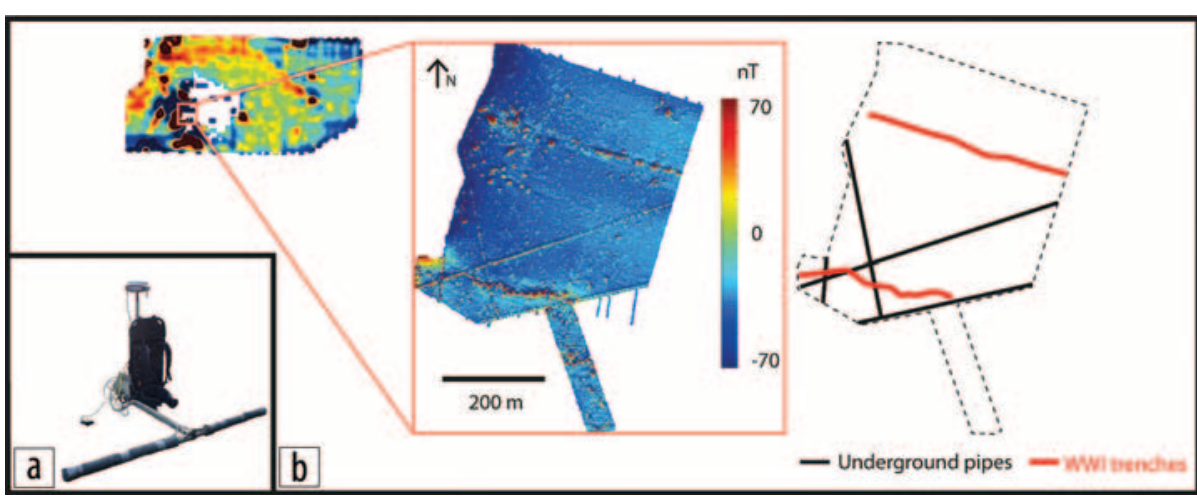

Figure 5. (a) Backpack-mounted ground device from IPGS. (b) Map of the magnetic anomalies obtained with the device $1 \mathrm{~m}$ above the ground and interpretation of the lineations.

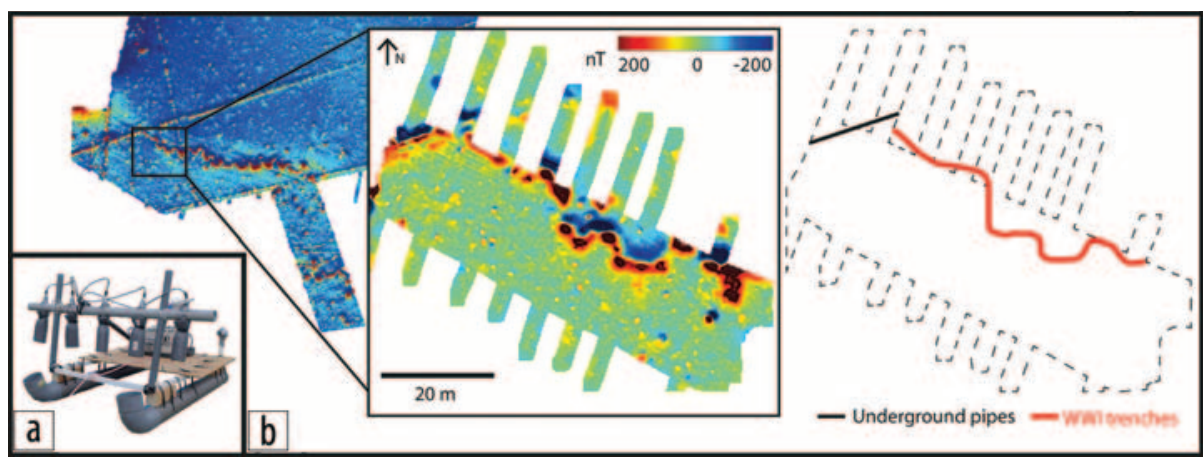

Figure 6. (a) Sledge-mounted ground device from IPGS. (b) Map of the magnetic anomalies obtained with the device at $0.2 \mathrm{~m}$ above the ground and interpretation of the lineation. due to the increased proximity of the sources. Thus, the survey also reveals subtler dipolar anomalies, probably linked to lighter UXO (Figure 6b).

\section{Conclusion}

With the recent advances in calibration and compensation of fluxgates, these types of magnetometers are interesting tools for multipurpose magnetic mapping. The lightness, ruggedness, and low power consumption of the sensors make them the instruments of choice for multisensor or vehicle-mounted devices. The electronics described here, coupled with the described fluxgate magnetometers, allow efficient ground surveys at a submetric scale (2000 to 10,000 $\mathrm{m}^{2}$ per hour). Mounted on UAV or light aircraft, they offer a wide range of speed and resolution of aeromagnetic maps. The case study shows the range of available applications: exploration, underground pipe identification, UXO evaluation, and archaeology. Further developments are focusing on the use of lighter drones able to fly less than $10 \mathrm{~m}$ above the ground and on light off-road vehicles. WL:

\section{Acknowledgments}

We thank Jerry Hensel for his comments and suggestions.
Corresponding author: bgavazzi@unistra.fr

\section{References}

Bronner, A., M. Munschy, D. Sauter, J. Carlut, R. Searle, and A. Maineult, 2013, Deep-tow 3C magnetic measurement: Solutions for calibration and interpretation: Geophysics, 78, no. 3, J15-J23, http://dx.doi.org/10.1190/geo2012-0214.1.

Munschy, M., D. Boulanger, P. Ulrich, and M. Bouiflane, 2007, Magnetic mapping for the detection and characterization of UXO: Use of multi-sensor fluxgate 3-axis magnetometers and methods of interpretation: Journal of Applied Geophysics, 61, no. 3-4, 168-183, http://dx.doi.org/10.1016/j.jappgeo. 2006.06.004.

Nabighian, M. N., V. J. S. Grauch, R. O. Hansen, T. R. LaFehr, Y. Li, J. W. Peirce, J. D. Phillips, and M. E. Ruder, 2005, The historical development of the magnetic method in exploration: Geophysics, 70, no. 6, 33ND-61ND, http://dx.doi.org/10.1190/1. 2133784.

Primdahl, F., 1979, The fluxgate magnetometer: Journal of Physics E, Scientific Instruments, 12, no. 4, 241-253, http://dx.doi. org/10.1088/0022-3735/12/4/001. 